\title{
INVENTORY POLICY FOR A DETERIORATING ITEM: QUADRATIC DEMAND WITH SHORTAGES
}

\author{
F.E.U. Osagiede, and A.A. Osagiede \\ Department of Mathematics, University of Benin, \\ Benin City, Nigeria.
}

\begin{abstract}
We develop an inventory model for a deteriorating item having an instantaneous supply with a quadratic time-varying demand given by $f(t)=a+b t+c t^{2} ; a \geq 0, b \neq 0, c \neq 0$ with shortages. The model is solved analytically to obtain the optimal solution for the problem. The sensitivity analysis of the optimal solution toward change in the values of the different system parameters is also examined. Numerical example is given to illustrate the proposed model.
\end{abstract}

Keywords: Inventory, deterioration, EOQ, sensitivity analysis, time-varying quadratic demand, shortages.

\section{INTRODUCTION}

The aim of the paper is to develop an EOQ (Economic order Quantity) model for a deteriorating single-item inventory for a quadratic demand with shortages. In formulating inventory models, two factors of the problem have been of growing interest to researchers, one being the deterioration of item and the other the variation in the demand rate with time.

The classical no-shortage inventory problem for a linear trend in demand over a finite timehorizon was solved analytically by Donaldson (1977). However, Donaldson's solution procedure was computationally complex. Osagiede and Omosigho $(2000 ; 2002 ; 2003)$ presented a simple procedure for adjusting the economic order quantity model for the case of increasing linear and Quadratic demand using the direct and the inverse approach. Omosigho and Osagiede (2004) developed an inventory model followed by constant demand. However, the possibilities of shortage and deterioration in inventory were left out of consideration in all these models.

Dave and Patel (1984) develop an inventory model for deteriorating items with time proportional demand. Bahari-Kashani (1980) discussed a heuristic model for obtaining order quantities when demand is time proportional and inventory deteriorates at a constant rate over time. Deb and Chaud-huri (1987) studied the inventory replen- 
ishment policy for items having a deterministic demand pattern with a linear (positive) trend and shortages. Chang and Dye (1999); Teng et al. (2003), Dye and Chang (2003), Goyal (1988); Dave (1989); Hariga (1994; 1995, 1996), Goswami and Chaud-huri (1991) Chung and Tin (1993, 1994), Kim (1995), Giri and Chaud-huri (1997), Lin et.al (2000), Jalan and Chaud-huri (1999) and Wee (1995) contributed to the inventory problems with deteriorating items with time varying demand incorporating shortages. They developed a heuristic inventory model to determine the decision rule for selecting the times and sizes of replenishment over a finite time horizon so as to keep the total inventory costs minimum.

The demand for a product experiences a period of rapid increase in sales during the growth phase of their life cycle. This is usually observe during the introduction of a new product into the market in which the product is competing to gain acceptance among consumers and before the maturity phase characterized by by a stable demand. Then the maturity phase is followed by a period of sales decline, which may be caused which may be caused by the introduction of the new product or by changes in consumer's preference. This is demonstrated by Hill (1996) which gives an example of a complete product life cycle.

In this paper, we develop an inventory model for a single-item inventory with a time-varying quadratic demand incorporating shortages. An analytical solution of the model is discussed. Sensitivity analysis of the optimal solution with respect to changes in the different parameter values is also examined. The model is illustrated with numerical example.

\section{NOTATIONS AND ASSUMPTIONS}

The following notations are used in the model.

$c_{1}$ - Ordering cost per order.

$c_{2}$ - inventory holding cost per unit per unit time..

$c_{3}-$ cost of a unit

$S$ - shortage cost per unit time. $q_{0}$ - quantity of the initial inventory.

$f(t)$ - demand rate at any time $t \geq 0$

$T$ - cycle time

$K$ - a constant value $(0 ; K ; 1)$

$t_{l} \quad$ - time when there is no shortage $\left(0 ; t_{l} ; T\right)$

$h(t)=a b t^{(\mathrm{b}-1)}$ be the instantaneous rate function, where $a$ and $b$ are the scale and the shape parameter respectively.

$T^{*}$-optimal value of $T$

$q_{o}{ }^{*}$-optimal value of $q_{0}$

$t_{1}{ }^{*} \quad$-optimal value of $t_{1}$

$K^{*}$-optimal value of $K$

\section{ASSUMPTIONS}

- $\quad$ The demand rate is $f(t)=a+b t+c t^{2} ; a^{3} 0, b^{1}$ $0, c^{1} 0$ where $a, b$ and $c$ are constants such that, $f(t)$ varies quadratically with time, $a$ is the initial demand rate and $b$ the positive trend in demand.

- Shortages in inventory are allowed.

- Replenishment is instantaneous and the lead time is zero.

- A deteriorated unit is not repaired or replaced during a given cycle.

- The holding cost, ordering cost, shortage cost and unit cost remain constant over time.

\section{MODEL FORMULATION AND SOLUTION}

Depletion of the inventory occurs due to the combine effects of the demand and deterioration. The differential equation governing the instantaneous state of the inventory level $q(t)$ at any time $t$ is given by

$$
\begin{aligned}
& \frac{d q(t)}{d t}+q(t) h(t)=-\left(a+b t+c t^{2}\right) \\
& 0 \leq t \leq t_{1} \\
& \text { with } q(0)=q_{0} \text { and } q\left(t_{1}\right)=0
\end{aligned}
$$

When $h(t)=0$ for every $t \hat{\mathrm{I}}\left[t_{l}, T\right]$ then Equation (1) reduces to

92 Journal of Science and Technology, Volume 27 no. 2, August, 2007 
$\frac{d q(t)}{d t}=-\left(a+b t+c t^{2}\right) \quad t_{1} \leq t \leq T$

The deterioration rate $h(t)$ is given by

$$
h(t)=\alpha \beta t^{(\beta-1)} \quad a>0, b>0, t>0 .
$$

by (4), (1) becomes

$\frac{d q(t)}{d t}+q(t) \alpha \beta t^{\beta-1}=-\left(a+b t+c t^{2}\right) \quad 0 \leq t \leq t_{1}$

Equation (5) is a linear ordinary differential equation of first order.

Multiplying both sides of equation (5) by the integrating factor and then integrating over $[0, t]$, we have

$q\left(\exp \left\{\alpha t^{\beta}\right\}\right)-q_{0}=-\int_{0}^{t}\left(a+b t+c t^{2}\right) \exp \left\{\alpha t^{\beta}\right\} d t$,

$0 \leq t \leq t_{1}$

Applying the initial conditions $q\left(\mathrm{t}_{1}\right)=0$, equation (6) becomes

$q_{0}=\int_{0}^{t_{1}}\left(a+b t+c t^{2}\right) \exp \left\{\alpha t^{\beta}\right\} d t$

Substituting equation (7) into equation (6), we have

$q(t)=\frac{\int_{0}^{t_{0}}\left(a+b t+c t^{2}\right) \exp \left\{\alpha t^{\beta}\right\} d t-\int_{0}^{(}\left(a+b t+c t^{2}\right) \exp \left\{\alpha t^{\beta}\right\} d t}{\left.\exp \alpha t^{\beta}\right\}}, 0 \leq t \leq t_{1}$

Equation (3) becomes

$q(t)=-\int_{t_{1}}^{(}\left(a+b t+c t^{2}\right) d t=a\left(t_{1}-t\right)+\frac{b}{2}\left(t_{1}^{2}-t^{2}\right)+\frac{c}{3}\left(t_{1}^{3}-t^{3}\right), \quad t_{1} \leq t \leq T$

Equation (9) is now the instantaneous level of inventory at any time $t \in\left[t_{1}, T\right]$.

The quantity at the beginning of the cycle must be sufficient enough to meet the total demand given by

$\int_{0}^{t_{1}}\left(a+b t+c t^{2}\right) d t=a t_{1}+\frac{b}{2} t_{1}^{2}+\frac{c}{3} t_{1}^{3}$
Hence the total quantity of deteriorated items is given by

$$
q_{0}-\int_{0}^{t_{1}}\left(a+b t+c t^{2}\right) d t=q_{0}-a t_{1}-\frac{b}{2} t_{1}{ }^{2}-\frac{c}{3} t_{1}^{3}
$$

Now if we express the exponential term in (6) in infinite series and then integrate term by term, we have

$q_{0}=a \sum_{n=0}^{\infty} \frac{\alpha^{n} t_{1}^{n \beta+1}}{(n \beta+1) n !}+b \sum_{n=0}^{\infty} \frac{\alpha^{n} t_{1}^{n \beta+2}}{(n \beta+2) n !}+c \sum_{n=0}^{\infty} \frac{\alpha^{n} t_{1}^{n \beta+3}}{(n \beta+3) n !}$

The average inventory holding cost in $\left[0, \mathrm{t}_{1}\right]$ is

$$
\frac{c_{2}}{2 T} q_{0} t_{1}
$$

The average inventory holding cost is taken here in the same form as it is used in deterministic EOQ models with no deterioration. Without this approximation, the model becomes "too complex" to solve.

The average shortage cost in $\left[t_{l}, T\right]$ is

$\frac{S}{T} \int_{t_{1}}^{T}\left(a+b t+c t^{2}\right)(T-t) d t$

$=\frac{S}{12 T}\left[\left(T-t_{1}\right)^{2}\left\{6 a+2 b\left(T+2 t_{1}\right)+c\left(T^{2}+2 T t_{1}+3 t_{1}^{2}\right)\right\}\right]$

Therefore, the total variable cost per unit time is given by

$$
\begin{aligned}
T c & =\frac{C_{3}}{T}\left(q_{0}-a t_{1}-\frac{b}{2} t_{1}^{2}-\frac{c}{3} t_{1}^{3}\right)+\frac{C_{2}}{2 T} q_{0} t_{1} \\
& +\frac{S\left(T-t_{1}\right)^{2}}{12 T}\left\{6 a+2 b\left(T+2 t_{1}\right)+c\left(T^{2}+2 T t_{1}+3 t_{1}^{2}\right)\right\}+\frac{C_{1}}{T}
\end{aligned}
$$

Since we know that the shortage interval is a part of the cycle time, we assume now

$t_{1}=K T, \quad 0<K<1$

where the constant $K$ is to be determined in an optimal approach. Substituting (14) into equation (7), equation (13) becomes,

$$
\begin{aligned}
T c & =\left(\frac{C_{3} a}{T}+\frac{C_{2}}{2} K a\right) \int_{0}^{K T} \exp \left\{\alpha t^{\beta}\right\} d t+\left(\frac{C_{3} b}{T}+\frac{C_{2}}{2} K b\right) \int_{0}^{K T} t \exp \left\{\alpha t^{\beta}\right\} d t \\
& +\left(\frac{C_{3} c}{T}+\frac{C_{2}}{2} K c\right) \int_{0}^{K T} t^{2} \exp \left\{\alpha t^{\beta}\right\} d t-C_{3} a K-\frac{C_{3} b}{2} K^{2} T-\frac{C_{3} c}{3} K^{3} T^{2} \\
& +\frac{C_{2}(1-K)^{2}}{2} a T+\frac{S(1-K)^{2}(1+2 K) b T^{2}}{6}+\frac{S(1-K)^{2}\left(1+2 K+3 K^{2}\right) c T^{3}}{12} \\
& +\frac{C_{1}}{T}
\end{aligned}
$$


Expressing the exponential terms of equation (15) in infinite series and then integrating term by term, we obtain

$$
\begin{aligned}
T c & =\left(\frac{C_{3} a}{T}+\frac{C_{2}}{2} K a\right) \sum_{n=0}^{\infty} \frac{\alpha^{n}(K T)^{n \beta+1}}{(n \beta+1) n !}+\left(\frac{C_{3} b}{T}+\frac{C_{2}}{2} K b\right) \sum_{n=0}^{\infty} \frac{\alpha^{n}(K T)^{n \beta+2}}{(n \beta+2) n !} \\
& +\left(\frac{C_{3} c}{T}+\frac{C_{2}}{2} K c\right) \sum_{n=0}^{\infty} \frac{\alpha^{n}(K T)^{n \beta+3}}{(n \beta+3) n !}+C_{3} a K-\frac{C_{3} b}{2} K^{2} T \\
& -\frac{C_{3} c}{3} K^{3} T^{2}+\frac{C_{2}(1-K)^{2}}{2} a T+\frac{S(1-K)^{2}(1+2 K) b T^{2}}{6} \\
& +\frac{S(1-K)^{2}\left(1+2 K+3 K^{2}\right) c T^{3}}{12}+\frac{C_{1}}{T}
\end{aligned}
$$

Equation (16) is now the optimum average cost for the inventory system.

\section{NUMERICAL ILLUSTRATION}

In this section, we present numerical results to illustrate the proposed method with the quadratic demand. The parameters are shown in Table 1.

Table 1: Parameters used to illustrate the proposed method

\begin{tabular}{ccccccccc}
\hline$a$ & $b$ & $c$ & $C_{1}$ & $\mathrm{C}_{2}$ & $C_{3}$ & $S$ & $\mathrm{a}$ & $b$ \\
10 & 2 & 1 & 20 & 0.001 & 4 & 10 & 0.002 & 1.5
\end{tabular}

Based on these input data, the optimal values of $\mathrm{T}^{*}, K^{\prime} q_{0}$ and $T^{*} \mathrm{c}$ the Total inventory cost for the case of quadratic demand are obtained as given in Table 2. Asterisks $\left(^{*}\right)$ indicates the optimum values.

To obtain $\mathrm{t}_{1}{ }^{*}$ using equation (14). We may then use equation (11) to determine the optimal Economic order quantity (EOQ) $\mathrm{q}_{0}{ }_{0}$ and equation (16) to calculate the optimal average cost. From Table 2, Optimum cycle time $\mathrm{T}^{*}=1.3532$ days, Optimum value $\mathrm{K}^{*}=0.630$, Economic order quantity $\mathrm{q}_{0}{ }^{*}=9.4647$ units, Optimum stockperiod $\mathrm{t}_{1}{ }^{*}=0.8525$ days and cost $\mathrm{TC}^{*}=36.4387$ per day.
Table 2: Results for the arbitrary choice of $K$ in the case of quadratic demand, *indicates the optimum value

\begin{tabular}{crrr}
\hline$K$ & $\mathrm{~T}^{*}$ & $\boldsymbol{q}_{0}{ }^{*}$ & \multicolumn{1}{c}{$T^{*} c$} \\
\hline 0.500 & 1.0645 & 5.6579 & 36.9193 \\
0.550 & 1.1566 & 6.8545 & 36.6591 \\
0.560 & 1.1776 & 7.1282 & 36.6224 \\
0.570 & 1.1993 & 7.4133 & 36.5818 \\
0.580 & 1.2220 & 7.7121 & 36.5438 \\
0.590 & 1.2457 & 8.0263 & 36.5109 \\
0.600 & 1.2706 & 8.3571 & 36.4835 \\
0.610 & 1.2967 & 8.7056 & 36.4607 \\
0.620 & 1.3242 & 9.0742 & 36.4457 \\
$0.630^{*}$ & $1.3532^{*}$ & $9.4647^{*}$ & $36.4387^{*}$ \\
0.640 & 1.3839 & 9.8799 & 36.4429 \\
0.650 & 1.4165 & 10.3224 & 36.4591 \\
0.660 & 1.4510 & 10.7950 & 36.4829 \\
\hline
\end{tabular}

\section{SENSITIVITY ANALYSIS}

In this section, we shall study the effect of changes in the values of the system parameters $a$, $b, c, C_{1}, C_{2}, C_{3}, S, a$ and $b$ on the optimal cost, cycle time and the EOQ given by the proposed method. Sensitivity analysis is done by changing the parameters by $-50 \%,-20 \%,+20 \%$ and $+50 \%$ on each parameter, while other parameters remain unchanged.

\section{REMARK}

Based on the results shown in the Table 3, the following observations can be made:

94 Journal of Science and Technology, Volume 27 no. 2, August, 2007 
Table 3: Table showing the sensitivity analysis

\begin{tabular}{|c|c|c|c|c|}
\hline $\begin{array}{l}\text { Changing } \\
\text { parameter }\end{array}$ & $\begin{array}{l}\% \text { change in the } \\
\text { system parameter }\end{array}$ & $\begin{array}{c}\text { \% change in } \\
T^{*}\end{array}$ & $\begin{array}{l}\text { \% change } \\
\text { in } q^{*}\end{array}$ & $\begin{array}{c}\text { \% change in } \\
T C^{*}\end{array}$ \\
\hline$A$ & $\begin{array}{r}-50 \\
-20 \\
+20 \\
+50\end{array}$ & $\begin{array}{r}14.01 \\
5.16 \\
-4.64 \\
-10.74\end{array}$ & $\begin{array}{r}-35.38 \\
-13.13 \\
12.02 \\
28.33\end{array}$ & $\begin{array}{r}-6.18 \\
-2.02 \\
1.29 \\
3.37\end{array}$ \\
\hline$B$ & $\begin{array}{r}-50 \\
-20 \\
+20 \\
+50\end{array}$ & $\begin{array}{r}5.57 \\
2.08 \\
-1.91 \\
-4.52\end{array}$ & $\begin{array}{r}2.01 \\
0.74 \\
-0.66 \\
-1.53\end{array}$ & $\begin{array}{r}1.94 \\
0.71 \\
-0.64 \\
-1.51\end{array}$ \\
\hline$C$ & $\begin{array}{r}-50 \\
-20 \\
+20 \\
+50\end{array}$ & $\begin{array}{r}2.47 \\
0.93 \\
-0.87 \\
-2.07\end{array}$ & $\begin{array}{r}1.60 \\
0.59 \\
-0.72 \\
-1.29\end{array}$ & $\begin{array}{r}0.63 \\
0.23 \\
-0.21 \\
-0.47\end{array}$ \\
\hline$C_{l}$ & $\begin{array}{r}-50 \\
-20 \\
+20 \\
+50\end{array}$ & $\begin{array}{r}-24.32 \\
-8.39 \\
7.28 \\
16.72\end{array}$ & $\begin{array}{r}-31.74 \\
-9.32 \\
8.24 \\
19.17\end{array}$ & $\begin{array}{r}-48.59 \\
-19.22 \\
19.01 \\
47.19\end{array}$ \\
\hline$C_{2}$ & $\begin{array}{r}-50 \\
-20 \\
+20 \\
+50\end{array}$ & $\begin{array}{r}0.007 \\
0.002 \\
-0.002 \\
-0.004\end{array}$ & $\begin{array}{r}0.008 \\
0.002 \\
-0.002 \\
-0.006\end{array}$ & $\begin{array}{r}-0.002 \\
-0.001 \\
0.001 \\
0.002\end{array}$ \\
\hline$C_{3}$ & $\begin{array}{r}-50 \\
-20 \\
+20 \\
+50\end{array}$ & $\begin{array}{r}-15.12 \\
-6.15 \\
6.35 \\
16.22\end{array}$ & $\begin{array}{r}-16.96 \\
-6.89 \\
7.13 \\
18.23\end{array}$ & $\begin{array}{r}-1.59 \\
-0.65 \\
0.68 \\
1.75\end{array}$ \\
\hline$S$ & $\begin{array}{r}-50 \\
-20 \\
+20 \\
+50\end{array}$ & $\begin{array}{r}34.20 \\
9.84 \\
-7.38 \\
-15.69\end{array}$ & $\begin{array}{r}40.13 \\
11.18 \\
-8.19 \\
-17.25\end{array}$ & $\begin{array}{r}0.39 \\
0.15 \\
-0.23 \\
-0.66\end{array}$ \\
\hline$a$ & $\begin{array}{r}-50 \\
-20 \\
+20 \\
+50\end{array}$ & $\begin{array}{r}0.04 \\
0.02 \\
-0.01 \\
-0.04\end{array}$ & $\begin{array}{r}0.013 \\
0.008 \\
-0.004 \\
-0.013\end{array}$ & $\begin{array}{r}0.008 \\
0.006 \\
-0.002 \\
-0.008\end{array}$ \\
\hline$\beta$ & $\begin{array}{r}-50 \\
-20 \\
+20 \\
+50\end{array}$ & $\begin{array}{r}0.03 \\
0.01 \\
-0.02 \\
-0.04\end{array}$ & $\begin{array}{r}0.055 \\
0.007 \\
-0.003 \\
-0.023\end{array}$ & $\begin{array}{r}0.05 \\
0.02 \\
-0.01 \\
-0.02\end{array}$ \\
\hline
\end{tabular}


(1). $T^{*}$ decreases while $\mathrm{q}_{0}{ }^{*}$ and $T C^{*}$ both increase with the increase in the value of the parameter $a$. However, $T C^{*}$ and $T^{*}$ have low sensitivity to changes in $\mathrm{a}$. On the other hand, $\mathrm{q}_{0}{ }^{*}$ has moderate sensitivity towards changes in $a$. (2). $T^{*}, T C^{*}$ and $\mathrm{q}_{0}{ }^{*}$ all decrease (increase) with the increase (decrease) of $b$. However, they are slightly sensitive to changes in $b$. (3). Each of $T^{*}, \mathrm{q}_{0}{ }^{*}$ and $T C^{*}$ decreases (increases) with the increase (decrease) of $c$ and they are slightly sensitive to changes in c. (4). Each of $T^{*}, \mathrm{q}_{0}{ }^{*}$ and $T C^{*}$ increases (decreases) with the increase (decrease) of $C_{l}$. They are all moderately sensitive to changes in $C_{I}$. (5). $T^{*}, \mathrm{q}_{0}{ }^{*}$ and $T C^{*}$ are all insensitive to changes in the parameter $C_{2}$. (6). $T^{*}, \mathrm{q}_{0}{ }^{*}, T C^{*}$ all decrease (increase) with the increase (decrease) of $S . T^{*}$ and $\mathrm{q}_{0}{ }^{*}$ are moderately sensitive while $T C^{*}$ is almost insensitive to changes in $S$. (7). Each of $T^{*}, \mathrm{q}_{0}{ }^{*}$ and $T C^{*}$ increases (decreases) with the increase (decrease) of $C_{3} \cdot \mathrm{q}_{0}{ }^{*}$ and $T^{*}$ have low sensitivity while $T C^{*}$ is almost insensitive to changes in $C_{3}$. (8). $T^{*}, \mathrm{q}_{0}{ }^{*}, T C^{*}$ are insensitive to changes in a. (9). $T^{*}, \mathrm{q}_{0}{ }^{*}, T C^{*}$ are insensitive to changes in $b$.

\section{CONCLUSION}

An analytic method for solving the inventory replenishment problem when the demand is time-varying quadratic demand $f(t)=a+b t+$ $c i^{2} ; a^{3} 0, b, c^{1} 0$ has been proposed. The proposed quadratic time-dependence demand seems to be a better representation of the time-varying market demands. This type of demand is quite appropriate for seasonal products. The demand rate undergoes an accelerated growth, which is found to occur in the case of spare parts, computers, etc. before a decline in demand. The effects of changes in the values (sensitivity analysis) of the system parameters are examined

\section{ACKNOWLEDGEMENTS}

The authors thank the anonymous referees for their valuable comments and suggestions, which greatly enhanced the clarity of the article.

\section{RERERENCES}

Bahari-Kashani, H. (1980). "Replenishment schedule for deteriorating items with timeproportional demand". Journal of Operational Research Society 40, 75-81.

Chang, H. J and Dye C-Y. (1999). "An EOQ model for deteriorating item with timevarying demand and partial backlogging", Journal of Operational Research Society 50 (11), 1176-1182

Chung, K.J, and Ting, P.S (1993). "heuristic for replenishment of deteriorating items with a linear trend in demand' Journal of operational Research Society, 44 (12), 1235 1241.

Chung, K.J, and Ting, P.S (1994). "On replenishment schedule for deriorating items with time proportional demand" Production Planning and control, 392-396

Dave, U. (1989). "On a heuristic inventory replenishment rule for items with a linearly increasing demand incorporating shortages". Journal of Operational Research Society, 40, 827-830.

Dave, U. and Patel, L. K. (T, Si), (1984). "Policy inventory model for deteriorating items with time proportional demand" Journal of $O p$ erational Research Society 32, 137-142.

Deb, M. and Chaudhuri, K. (1987). "A note on the heuristic for replenishment of trended inventories considering shortages". Journal of Operational Research Society 38, 459463.

Donaldson, W. A. (1977). "Inventory replenishment policy for a linear trend in demand- an analytical solution. Operational Research Quarterly, 28, 663-670

Giri, B.C and Chaudhuri, K. S (1997). "Heuristic model for deteriorating items with shortages and time-varying demand and costs" International Journal of System Science, 28 (2), 153-159

96 Journal of Science and Technology, Volume 27 no. 2, August, 2007 
Goswami, A. and Chaudhuri, K. S. (1991). "An EOQ model for deteriorating items with a linear trend in demand". Journal of Operational Research. Society, 42 (12), 11051110.

Hariga, M. (1996). "Optimal EOQ models for deteriorating items with time-varying demand". Journal of Operational Research Society, 47, 1228-1246.

Hariga, M. (1994). "The inventory lot-sizing problem with continuous time-varying demand and shortages". Journal of Operational Research Society, 45 (7), 827- 837.

Hariga, M. (1995). “An EOQ model for deteriorating items with shortages and time-varying demand". Journal of Operational Research Society, 46, 398 - 404.

Hill R.M (1996). "Batching policies for a product life cycle" International Journal of Production Economics, 45, 421-427

Jalan, A. K and Chaudhuri, K. S (1999). "An EOQ models for deteriorating items in a declining market with SFI policy" Korean Journal of Computational and Applied Mathematics, 6 (2), 437- 449.

Kim, D.H (1995). "A heuristic for replenishment of deteriorating items with a linear trend in demand" International Journal of Production Economics, 39, 265-270.

Lin, C., Tan, B. and Lee, W.C (2000). “An EOQ models for deteriorating items with timevarying demand and shortages". International Journal of System Science, 31 (3) 390 -400 .
Omosigho, S. E. and Osagiede, F. E. U (2004). "On Inventory model with increasing demand followed by constant demand", J. of the Mathematical Association of Nigeria (ABACUS), 31(2b), 214 - 222

Osagiede, F. E. U and Omosigho, S. E. (2000). "Inventory replenishment policy when demand is quadratic: Direct and Inverse method", Journal of the Nigerian Association of Mathematical Physics: 4, 301-308.

Osagiede, F. E. U. (2002). "Inventory control models for items with time dependent increasing demand". Ph.D thesis, University of Benin, Benin City, Nigeria.

Osagiede, F. E. U and Omosigho, S. E. (2003). "A simple inventory replenishment rule for product with linear increasing trend in demand" The Nigerian Journal of Economic and Financial Review, 8, 35-46

Teng J. T., Yang H-L., and Ouyang. L-Y., (2003). "On an EOQ model for deteriorating item with time- varying demand and partial backlogging" Journal of Operational Research Society 54, 432 - 436.

Wee, H. M. (1995). "A deterministic lot-size inventory model for deteriorating items with shortages and a declining market" Computer and Operations Research, 22 (3), 345-356. 